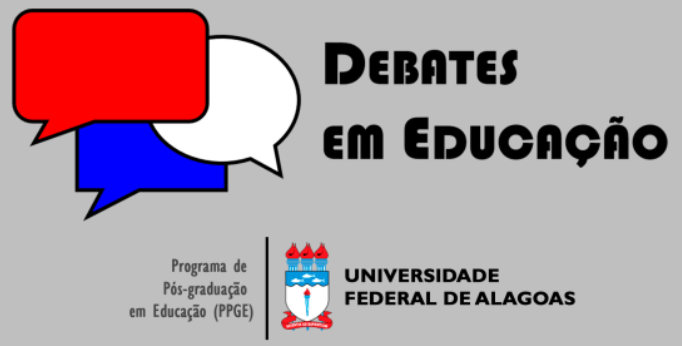

ISSN Eletrônico 2175-6600

Vol. 12 | Número Especial | 2020

Preciosa Fernandes

Universidade do Porto (UP - Portugal) preciosa@fpce.up.pt

Ana Maria Tavares Duarte

9 iD

Universidade Federal de Pernambuco (UFPE) familliaduarte@uol.com.br

\section{EDUCAÇÃO INCLUSIVA DE PESSOAS COM DEFICIÊNCIA NO BRASIL: CONSTRUINDO PONTES ENTRE DISCURSOS POLITICOS E DISCURSOS TEÓRICO-CURRICULARES}

\section{RESUMO}

A educação inclusiva da pessoa com deficiência no Brasil, embora se reconheça existir atenção política para esta problemática desde pelo menos a Constituição de 1988 , parece estar ainda longe de ser alcançada. Tem-se claro que a concretização da educação inclusiva requer a adoção de práticas curriculares flexíveis e diferenciadas que assegurem que todos os alunos possam conviver e aprender juntos. É neste âmbito que se situa o estudo que neste artigo se dá conta, cujo objetivo foi analisar proposições políticas e teórico-curriculares sobre Educação Inclusiva no Brasil, problematizando possibilidades de concretização. Recorreu-se à análise documental da legislação brasileira e a artigos, com foco em práticas curriculares de inclusão, publicados na plataforma Scielo. Os resultados apontam para pontes ténues entre o discurso legal e discursos acadêmicos sobre práticas curriculares inclusivas.

Palavras-chave: Educação inclusiva. Pessoas com deficiência. Discursos e práticas curriculares.

\section{INCLUSIVE EDUCATION OF DISABLED PEOPLE IN BRAZIL: BUILDING BRIDGES BETWEEN POLITICAL AND THEORETICAL-CURRICULAR DISCOURSES}

\begin{abstract}
Inclusive education for people with disabilities in Brazil, despite recognizing that there has been political attention to this problem since at least the constitution of 1988 , seems to be far from being achieved. It is clear that the achievement of inclusive education requires the adoption of flexible and differentiated curricular practices that ensure that all students can live and learn together. It is in this context in which the study is situated, whose objective was to analyze political and theoretical-curricular proposals on Inclusive Education in Brazil, problematizing possibilities of implementation. Documentary analysis of Brazilian legislation and articles were used, focusing on curricular inclusion practices, published on the Scielo platform. The results point to tenuous bridges between the legal discourse and academic discourses on inclusive curricular practices.
\end{abstract}

Keywords: Inclusive education. Disabled people. Curriculum practices and discourses.

Submetido em: 25/03/2020

Aceito em: 25/05/2020

Publicado em: 10/12/2020

do http://dx.doi.org/10.28998/2 I75-6600.2020v I 2nEspp5|4-535 


\section{INTRODUÇÃO}

Historicamente, a ideia de inclusão está associada às pessoas com deficiência e à percepção de que se encontram em situação de desvantagem. Esta representação foi se sedimentando no imaginário coletivo e repercutindo em atitudes discriminatórias e excludentes que deram lugar à adoção de políticas assistencialistas.

Na década de 90, por força da Organização das Nações Unidas para Educação, a Ciência e a Cultura (UNESCO) e, particularmente com a Declaração de Salamanca ( 1994), assiste-se a uma evolução no modo de ver as pessoas com deficiência, e de se pensar a educação. Essa declaração foi essencial na proclamação do princípio de que todos os alunos devem "aprender juntos" na escola regular, independentemente das suas necessidades. Essa mudança na atenção social às pessoas com deficiência e suas possibilidades de relação em contextos educacionais regulares configura o primeiro passo que caracteriza o processo de integração e, posteriormente, de inclusão.

No caso do Brasil, há o reconhecimento de que, a nível político, o caminho tem sido o de investir numa educação inclusiva desde a Constituiçã̃o de 1988, com a instituição do direito de todos à educação. Relativamente aos alunos com deficiência proclama-se, então, a existência de um atendimento educacional especializado, preferencialmente na rede regular de ensino (art. 208). Todavia, apesar desta determinação, e do número de matrículas de alunos com deficiência ter vindo a aumentar (BRASIL, 20I3), tem vindo a questionar-se sobre o caminho ainda não percorrido para a concretização de uma educação inclusiva (RAZABONI JUNIOR; LEÃO JUNIOR; SANCHES, 20I8).

Reconhece-se que o discurso político sobre inclusão é dissonante das práticas do quotidiano nas escolas, admitindo-se que práticas de inclusão não são ainda uma realidade no Brasil (LAPLANE, 20 I 5).

É no quadro desta argumentação que se situa o estudo que neste artigo se apresenta. Com ele pretendeu-se analisar proposições políticas e teórico-curriculares sobre Educação Inclusiva no Brasil, problematizando possibilidades de sua concretização.

\section{CONCEITUANDO A EDUCAÇÃO INCLUSIVA}

O conceito de inclusão está, na sua origem, associado ao campo da educação especial e à ideia de necessidades educativas especiais (CORREIA, 200I; RODRIGUES, 2017; CORREIA; FERNANDES, 2016; ARMSTRONG; 20I4), remetendo para uma intervenção educativa direcionada a pessoas vulneráveis, e em risco de exclusão escolar. Essa associação está também presente na Declaração de 
Salamanca (1994), quer na renovação do compromisso de uma Educação para Todos ${ }^{1}$, quer pelas recomendações nela produzidas, entre outras a de que "as crianças e jovens com necessidades educativas especiais devem ter acesso às escolas regulares, que a elas se devem adequar através duma pedagogia centrada na criança, capaz de ir ao encontro destas necessidades", (preâmbulo).

Este enunciado, à data, veicula uma concepção de educação assente na ideia de que os alunos devem aprender juntos, independentemente das suas necessidades/incapacidades, e uma visão de escola entendida como espaço promotor da integração de todos os alunos no ensino regular capaz de responder de forma adequada às suas necessidades educativas. Vislumbrando-se princípios de uma educação inclusiva reconhece-se, todavia, que foi o modelo de integração que imperou durante a década de 90, tendo, posteriormente, sido questionado, sobretudo por se reconhecer o seu caráter normalizador (AINSCOW, 1997) e o risco que a ele está associado de excluir todos aqueles que "se afastam da norma", entre os quais as crianças com deficiência.

Sobre o significado da inclusão Guijarro (2005, p. 8-10) aponta quatro importantes argumentos justificativos para adoção de uma orientação educacional que atenda à diversidade dos alunos, e que possibilite transformar substancialmente a cultura excludente das escolas. Para esta autora a inclusão é uma questão de direitos, ou seja, de tornar efetivo o direito à educação, já consagrado na Declaração de Direitos Humanos (ONU, 1948). Um segundo aspecto prende-se com o entendimento da inclusão como um meio para garantir uma maior equidade, e a construção de escolas inclusivas como forma para se avançar para sociedades mais justas, em linha com pressupostos educacionais expressos na declaração de Salamanca (ONU, 1994). O terceiro argumento em defesa da educação inclusiva tem a ver com o respeito à diversidade humana, reconhecida como uma oportunidade para o enriquecimento dos processos de ensino-aprendizagem e para a melhoria da qualidade da educação. Esse posicionamento problematiza o enfoque homogeneizador de agrupamentos de alunos por critérios de semelhanças, quando os estudos têm mostrado que a heterogeneidade dos alunos é um fator que contribui para o êxito na aprendizagem. O quarto e último argumento é o de que a inclusão promove o desenvolvimento de valores de justiça, solidariedade e igualdade, e possibilita o "aprender a viver juntos" e o "aprender a ser".

Pese embora o conceito tenha vindo a ampliar-se de sentido, reconhece-se ser ainda um conceito evasivo, não consensualizado, e alvo de interpretações várias, "dependendo de quem utiliza o termo, em que contexto e com que finalidade" (ARMSTRONG, 2014, p. 13-14). Reportando-se ao contexto britânico o autor advoga que o termo "inclusão" tem sido utilizado em documentos oficiais de forma

\footnotetext{
' Esse princípio foi proclamado na Conferência de Educação para Todos, realizada em Jomtiem, Tailândia, em I990, na qual se quer questionou a situação de exclusão educacional de crianças e jovens em todos os países. Esta Conferência foi promovida pelo Banco Mundial, Organização das Nações Unidas para Educação, a Ciência e a Cultura (UNESCO), Fundo das Nações Unidas para Infância (UNICEF) e Programa das Nações Unidas para o Desenvolvimento (PNUD), sendo então aprovada a Declaração Mundial sobre Educação para Todos.
} 
"inconsistente (...) relacionando-o (quer) com políticas relativas aos alunos com necessidades educativas especiais", quer com a ideia de "educação inclusiva" , o que parece refletir a permanência de uma certa ambiguidade discursiva sobre o conceito de inclusão.

A partir do pensamento de Booth (2002), Armstrong (2014) convoca a ideia de reconhecimento e de participação como condições para a educação inclusiva. O reconhecimento é entendido na perspectiva de Fraser (2007, p. I I I ) "como uma questão de justiça". Neste racional a autora argumenta sobre a ideia de se pensar como injusto o fato de

A alguns indivíduos e grupos (ser) negada a condição de parceiros integrais na interação social, simplesmente em virtude de padrões institucionalizados de valoração cultural, de cujas construções eles não participaram em condições de igualdade, e os quais depreciam as suas características distintivas ou as características distintivas que lhes são atribuídas (FRASER, 2007, p. II2).

A ideia de participação, por seu lado, tem a ver com o sentido de pertença "à comunidade, tendo acessos e direitos iguais aos outros" (ARMSTRONG, 2014, p. 15), requerendo, segundo o autor, que a educação inclusiva atenda a estes dois aspectos. Por suas próprias palavras, educação inclusiva requer

Que toda a criança e jovem tenha o direito de frequentar a sua escola ou universidade locais (i.e., todos participam), e que todos os membros da escola ou universidade, ou mesmo da comunidade mais alargada, tenham o direito ao reconhecimento nos termos daquilo que são a sua cultura e crenças, aparências, interesses, estilo de vida e autenticidade. (ARMSTRONG, 20।4, p. I5).

Ainda na perspectiva de Armstrong (20|4) a inclusão pressupõe reconhecer a diversidade, enquanto direito de "sermos nós próprios" (ibidem). Nesta mesma linha também, Rodrigues (2014, p. 84) advoga que, na "perspectiva da inclusão, a diferença não constitui um problema em si, mas, sim, um desafio". Para o autor, responder "ao desafio da inevitável heterogeneidade" solicita à escola a capacidade de se modificar de modo a "proporcionar uma educação de qualidade a todos os seus alunos" (ibidem), numa lógica de inclusão e de promoção de equidade.

Pensando nas pessoas com deficiência, assegurar uma educação inclusiva, como lembrou Correia (200I, p. 125), pressupõe "que todos os alunos, com as mais diversas capacidades, interesses, caraterísticas e necessidades, possam aprender juntos, que seja dada atenção ao seu desenvolvimento, (...), que se crie um verdadeiro sentido de igualdade de oportunidades (...) que vise o sucesso escolar".

Numa leitura mais ampla, para Armstrong (2014, p. 15) "a educação inclusiva implica uma transformação na vida social, cultural, curricular e pedagógica da escola, assim como na sua organização física". Este desafio continua a justificar investimento em políticas que assegurem o direito de todos à educação e a garantia de verem atendidas as suas necessidades e interesses. É neste enquadramento que a Agenda 2030 para o Desenvolvimento Sustentável enuncia, entre outros, o objetivo de garantir uma educação de qualidade inclusiva, equitativa e promover oportunidades de aprendizagem ao longo da vida para 
todos (Objetivo 4). Reportando-nos às pessoas com deficiência, em foco neste artigo, pese embora sejam referenciadas no ponto 4, b do referido objetivo, não lhes é dado um destaque especial.

Nesse sentido, e no que a este grupo social diz respeito, considera-se que não sendo o processo de inclusão um desafio menor, não é também um desafio novo. Como é enunciado pela Unesco (2019, p. 13), as pessoas com deficiência "sempre estiveram em situação de maior desvantagem, ocupando no imaginário coletivo, a posição de alvos da caridade popular e da assistência social, e não de sujeitos de direitos sociais, entre os quais se inclui o direito à educação". Este organismo internacional tem tido uma relevante função na disseminação de um discurso de apelo ao reconhecimento da diversidade dos alunos como "oportunidades para aprimorar e democratizar a aprendizagem de todos os alunos" (prefácio), e da escola como um lugar privilegiado para a construção de uma educação mais democrática, promotora de maior justiça social (FRASER, 2007). Como sublinha Guijarro (2005, p. 10) "as escolas são locais centrais para o desenvolvimento de atividades de solidariedade, cooperação, respeito e valorização das diferenças, contribuindo de forma explícita para o desenvolvimento de uma cultura de paz e de sociedades mais justas e democráticas".

Mas, não sendo novo o desafio da inclusão continua a ser reconhecido como um objetivo em torno do qual todos os países continuem a investir em políticas que garantam a prevenção de todas as formas de discriminação e de exclusão (UNESCO, 2019). Com efeito, um dos desafios que continua a colocar-se aos sistemas educacionais consiste na capacidade em conseguir que todos os alunos, independentemente das suas diferenças, consigam ter sucesso em seu processo de aprendizagem. Ou, dito de outra maneira, a busca pela inclusão continua a ser um objetivo político prioritário e um objetivo central da educação escolar (ONU, 2016; UNESCO, 2019).

Neste domínio da educação escolar, e tendo em conta a realidade do Brasil, a adoção de práticas inclusivas pressupõe um entendimento do currículo amplo e flexível que possa ser diversificado e adaptável às diferenças sociais, culturais e individuais (BRASIL, 200I). Um currículo que precisa ser contextualizado às situações reais (FERNANDES; LEITE; MOURAZ; FIGUEIREDO, 20I3) para ser significativo e pertinente para todos os alunos.

\section{EDUCAÇÃO INCLUSIVA E ORGANIZAÇÃo dO CURRÍCULO - ALGUMAS CONSIDERAÇÕES}

No quadro dos pressupostos de uma educação inclusiva, e da complexidade das questões sociais, a escola tem sido obrigada a "repensar-se e a repensar os modos como se organiza e como configura e desenvolve o currículo escolar" (LEITE; FERNANDES, 2007, p. I21). A educação inclusiva problematiza as formas de organização curricular instituídas através das políticas públicas de educação, e conduz à 
interpelação dos processos de ensino-aprendizagem que não atendam à diversidade dos alunos e às suas reais necessidades cognitivas, relacionais e afetivas.

Carvalho (2008, p. 104), sustenta que um projeto curricular orientado para a inclusão e participação de todos os alunos "desenvolverá nos educandos habilidades e competências cognitivas, relacionais, afetivas, e políticas reconhecendo as características diferenciadas de seus corpos e organismos". Ou seja, para que um projeto curricular possa assegurar que todos os alunos realizem aprendizagens ricas, é necessário que o seu desenvolvimento se faça de forma flexível, acompanhando os diferentes ritmos e estilos de aprendizagem dos alunos.

No contexto brasileiro, a reflexão sobre aspectos curriculares, no que se refere à educação inclusiva de pessoas com deficiência, reafirma-se através de incursões no pensamento de Freire (1987) ao propor uma "Pedagogia do Oprimido" baseada na realidade social em que educador e educando estão inseridos, valorizando a bagagem sócio histórica e cultural que cada um traz consigo.

Esse posicionamento está em sintonia com uma perspectiva de educação multicultural crítica (STOER, 1994) promotora de um diálogo intercultural que valorize as diferenças e as reconheça como fator de enriquecimento de cada um e de todos. Do ponto de vista curricular, esta concepção de educação coloca a ênfase na importância de se atender à diversidade cultural em presença nas escolas fazendo uso de estratégias pedagógicas diferenciadas que promovam aprendizagens para todos (ROLDÃO, 2003). Com efeito, a ideia de concretização de uma educação inclusiva pressupõe, como referimos, a adopção de uma visão de currículo com possibilidades de ser contextualizado às realidades sociais, culturais e individuais dos alunos (FERNANDES; FIGUEIREDO, 20I2; CARVALHO, 2008); (GONZÁLEZ, 2002; LEITE; FERNANDES; FIGUEIREDO, 2019). Pressupõe, por outro lado uma concepção de escola aberta à pluralidade e heterogeneidade dos alunos, reconhecendo-os e valorizando-os, nas suas diferenças e idiossincrasias. Pressupõe, finalmente, uma concepção de professor aberto à mudança, com predisposição para uma permanente aprendizagem indutora da construção de práticas curriculares orientadas para a inclusão. Conjugar estes pressupostos representa um grande desafio para uma escola que se deseja, efetivamente, inclusiva. Ou, como sublinha Beyer (2009), o grande desafio parece ser o de se conseguir

Pôr em prática no ambiente escolar, uma pedagogia que consiga ser comum ou válida para todos os alunos da classe escolar, porém capaz de atender os alunos cujas situações pessoais e características de aprendizagem requeiram uma pedagogia diferenciada. (BEYER, 2009, p. 76).

Essa pedagogia diferenciada, constitui a base para o desenvolvimento de um currículo inclusivo promotor de aprendizagens para todos significativas. 


\section{METODOLOGIA}

O estudo é de natureza qualitativa, com recurso à pesquisa documental e teórica. Foi realizada análise de legislação sobre educação inclusiva no Brasil - desde a Constituição de 1988 até à atualidade - e de artigos que, de forma mais ou menos central, apresentavam reflexão sobre práticas curriculares de inclusão, publicados na base de dados Scielo do Brasil, entre 2008 e 2018.

No que respeita à pesquisa documental, o Quadro I sistematiza os documentos legais analisados.

\section{Quadro I - Documentos legais analisados.}

\begin{tabular}{|c|c|}
\hline Lei & Ano \\
\hline Constituição da República Federativa do Brasil. & 1988 \\
\hline LDBEN no 9.394/96 - Lei de Diretrizes e Bases da Educação Nacional. & 1996 \\
\hline $\begin{array}{l}\text { Resolução n 2/200 I CNE/CEB - Conselho Nacional de Educação/Câmera de Educação Básica - institui as } \\
\text { Diretrizes Nacionais para a educação de alunos que apresentem necessidades educacionais especiais, na } \\
\text { Educação Básica, em todas as suas etapas e modalidades. }\end{array}$ & 2001 \\
\hline Portaria n 2678/02 MEC - Estabelece diretrizes e normas para utilização, ensino e difusão do sistema Braille. & $2002 \mathrm{a}$ \\
\hline $\begin{array}{l}\text { Lei no } 10.436 / 02 \text { - Língua Brasileira de Sinais reconhece a língua brasileira de sinais como meio legal de } \\
\text { comunicação e expressão para pessoa surda. }\end{array}$ & $2002 b$ \\
\hline Política Nacional de Educação Especial na Perspectiva da Educação Inclusiva. & 2008 \\
\hline $\begin{array}{l}\text { Decreto n } 6.571 / 2008 \text { - Aprova a Grafia Braille para a Língua Portuguesa e recomenda o seu uso em todo o } \\
\text { território nacional. }\end{array}$ & 2008 \\
\hline $\begin{array}{l}\text { Resolução no } 4 \text { CNE/CEB - Conselho Nacional de Educação/Câmera de Educação Básica - Institui diretrizes } \\
\text { operacionais para o atendimento Educacional Especializado na Educação Básica. }\end{array}$ & 2009 \\
\hline Lei no $13 . \mid 46$ - Lei Brasileira de Inclusão da Pessoa com Deficiência. & 2015 \\
\hline
\end{tabular}

Fonte: elaborado pelas pesquisadoras.

Quanto à pesquisa teórica, foram selecionados artigos, escritos em português, publicados na plataforma Scielo do Brasil no período referido. A identificação dos artigos foi feita com base nos seguintes descritores: "Educação Inclusiva e inclusão escolar", "Práticas de Inclusão na escola" e "Inclusão e formação de Professores"; "Inclusão e práticas curriculares".

No total foram identificados 56 artigos. Desses, foram excluídos artigos que não se relacionavam com o contexto brasileiro, e que se referiam à práticas de inclusão no mercado de trabalho, na universidade, na educação infantil ou nos serviços de saúde. Foram, numa segunda fase, selecionados para análise 13 artigos que foram sujeitos a análise de conteúdo (KRIPPENDORF, 2003; AMADO, 20I3; THARENOU; DONOHUE; COOPER, 2007). Esses artigos estão sistematizados no quadro 2 (seção Apresentação e Análise dos dados) e são objeto de análise no ponto 5.2 deste artigo. 


\section{APRESENTAÇÃO E ANÁLISE DOS DADOS}

Como se deu conta na seção anterior, o presente estudo visa analisar legislação sobre educação inclusiva no Brasil desde a Constituição da República Federativa do Brasil (1988), e artigos com foco em práticas curriculares na escola, publicados na plataforma Scielo do Brasil nos últimos dez anos (2008-20 I 8). A apresentação dos dados faz-se em dois principais tópicos: i) Políticas de Educação Inclusiva no Brasil e seus enfoques; ii) Inclusão e práticas curriculares: um olhar a partir da produção acadêmica. No último ponto Construindo pontes entre os discursos legais e discursos acadêmicos avança-se para uma leitura articulada entre os dados que configura as considerações finais/conclusões do estudo.

\section{I Políticas de Educação Inclusiva no Brasil e seus enfoques}

Partindo da análise da Constituição da República Federativa do Brasil (1988) nela é referida a "educação como um direito de todos, garantindo o pleno desenvolvimento da pessoa, o exercício da cidadania e a qualificação para o trabalho" (Art. 205). O mesmo documento estabelece a "igualdade de condições de acesso e permanência na escola" como um dos princípios para o ensino (Art. 206, inciso l) e determina sobre "a oferta do atendimento educacional especializado, preferencialmente na rede regular de ensino, o acesso aos níveis mais elevados do ensino, de pesquisa e da criação artística, segundo a capacidade de cada um e ainda o acesso obrigatório e gratuito como direito público e subjetivo" (Art. 208). Observa-se, a partir destes segmentos discursivos, que este diploma legal estabelece a matriz dos princípios fundadores de uma educação inclusiva no Brasil, ao mesmo tempo que enuncia, como condições para a sua concretização, o atendimento especializado em contexto regular de ensino.

Quase uma década depois, a Lei n. 9.394/96 de Diretrizes e Bases da Educação Nacional (LDBEN) confere responsabilidade, em matéria educacional, às diversas entidades federativas: União, Distrito Federal, Estados e Municípios, sendo que a cada uma delas compete organizar o seu sistema de ensino, cabendo à União a coordenação da política nacional de educação, articulando os diferentes níveis e sistemas e exercendo função normativa, redistributiva e supletiva (Art. $8^{\circ}, 9^{\circ}, 10^{\circ}$ e $11^{\circ}$ ). Prosseguindo com os princípios enunciados na Constituição, reafirma-se, no texto desta lei, o princípio de uma educação para todos, promovendo o pleno desenvolvimento dos alunos e a sua preparação para o exercício da cidadania e a qualificação para o mundo do trabalho (Art. $2^{\circ}$ ). No tocante ao currículo é preconizada uma concepção de currículo que incluí aspectos básicos envolvendo fundamentos pedagógicos, filosóficos, sociopolíticos e tecnológicos (Art. 26.).

A discussão sobre currículo e pessoa com deficiência na LDBEN está referendada no Art. 59, inciso I, no qual pode-se ler que os sistemas de ensino deverão assegurar "currículos, métodos, técnicas, recursos 
educativos e organização específicos para atender às suas necessidades". No que respeita à intervenção de alunos com necessidades especiais, no inciso III do mesmo artigo é determinada a importância de existirem "professores com especialização adequada em nível médio ou superior, para o atendimento educacional especializado, bem como professores do ensino regular capacitados para a integração desses educandos nas classes comuns". A mesma Lei prevê, ainda, a adoção de atividades que favoreçam o aprofundamento e o enriquecimento de aspectos curriculares de alunos que apresentam superdotação, de forma a que sejam desenvolvidas as suas potencialidades, permitindo-Ihes concluir em menor tempo a educação básica, (Art. 24, inciso V "c"). Parece poder inferir-se, pelas propostas/práticas de concretização para que apontam estes excertos da lei, uma visão de educação mais na linha da integração do que da inclusão, ainda que se denote uma certa preocupação com a adequação e flexibilização do currículo de acordo com as necessidades e interesses dos alunos.

Um enfoque em processos de adequação curricular é também identificado na Resolução n. 2/200 I do Conselho Nacional de Educação/Câmera de Educação Básica (CNE/CEB), quando no Art. 8 , inciso III, se prevê "flexibilização e adaptações curriculares que considerem o significado prático e instrumental dos conteúdos básicos, metodologias de ensino e recursos didáticos diferenciados e processos de avaliação adequados ao desenvolvimento dos alunos que apresentam necessidades educacionais especiais, em consonância com o projeto pedagógico da escola". A Diretriz dispõe sobre o caráter substitutivo da educação para realizar o atendimento educacional especializado, pois além de complementar ou suplementar a escolarização, admite a possibilidade de a educação especial substituir o ensino em classe regular.

Com focagem na difusão do Sistema Braille, a Portaria n. 2.678/02 (BRASIL,2002a) , aprova diretrizes e normas sobre a difusão, e uso, do Sistema Braille em todas as modalidades de ensino, compreendendo o Projeto Grafia Braille para a Língua Portuguesa e a recomendação para o seu uso em todo território nacional. Esta parece ser uma politica de atenção à diversidade e de promoção da educação inclusiva no Brasil.

Também o reconhecimento, através da Lei n. 10.436/02 (BRASIL,2002b), da Língua Brasileira de Sinais - LIBRAS - como meio legal de comunicação e expressão, bem como a inclusão de uma disciplina de LIBRAS como parte integrante do currículo nos cursos de formação inicial de professores e de fonoaudiologia, constituem sinais políticos de maior atenção à diversidade e de proclamação de princípios de uma educação inclusiva.

Em janeiro de 2008, foi publicada a Política Nacional de Educação Especial na Perspectiva da Educação Inclusiva instituída pela Portaria n. 948, de 2007. O objetivo dessa Portaria foi assegurar a inclusão escolar de alunos com deficiência, transtornos globais do desenvolvimento e altas habilidades/superdotação, orientando os sistemas de ensino para garantir: acesso ao ensino regular, com 
participação, aprendizagem e continuidade nos níveis mais elevados do ensino; transversalidade da modalidade da educação especial desde a educação infantil até a educação superior; oferta do atendimento educacional especializado; formação de professores para o atendimento educacional especializado e demais profissionais da educação para a inclusão; participação da família e da comunidade; acessibilidade arquitetônica, nos transportes, nos mobiliários, nas comunicações e informação; e articulação intersetorial na implementação das políticas públicas. Depreende-se deste normativo uma visão de inclusão não remetida à ideia de deficiência, mas sim ampliada à ideia de atenção às diversidades em presença na escola. Corrobora esta inferência as ideias de uma aprendizagem articulada e o estímulo à participação da família e da comunidade são elementos, bem como a indicação de uma formação orientada para a educação inclusiva para todos os professores.

O Decreto presidencial n. 6.57//2008, cujo objetivo foi o de comprometer a União na prestação de apoio técnico e financeiro aos sistemas públicos de ensino dos Estados, do Distrito Federal e dos Municípios, vem fortalece a Política Nacional da Educação Especial na Perspectiva da Educação Inclusiva. Um ano mais tarde, foram instituídas as Diretrizes Operacionais para o Atendimento Educacional Especializado, através da Resolução n. 4/2009 para apoiar a implementação do Decreto n. 6.57I/2008, já citado. No artigo 2 dessa Resolução foi reafirmada a função complementar ou suplementar do Atendimento Educacional Especializado - AEE e a disponibilização dos recursos de acessibilidade. Essa função é, assim, especificada no parágrafo único dessa diretriz:

Para fins destas Diretrizes, consideram-se recursos de acessibilidade na educação aqueles que asseguram condições de acesso ao currículo dos alunos com deficiência ou mobilidade reduzida, promovendo a utilização dos materiais didáticos e pedagógicos dos espaços, dos mobiliários e equipamentos, dos sistemas de comunicação, dos transportes e demais serviços (BRASIL, 2009).

Foram, nesse âmbito, criadas as salas de recursos multifuncional voltadas para a oferta do atendimento educacional especializado.

Nesta trajetória política, foi instituída a Lei Brasileira de Inclusão da Pessoa com Deficiência, Lei n. 13. I 46/20 I 5 (Estatuto da Pessoa com Deficiência), destinada a assegurar e a promover, em condições de igualdade, o exercício dos direitos e das liberdades fundamentais de pessoa com deficiência, visando a sua inclusão social e cidadania plena. No Art. 28 desta Lei, com foco no direito à educação, pode observarse, entre outras questões, uma atribuição ao poder público para assegurar, criar, desenvolver, implementar, incentivar, acompanhar e avaliar um sistema educacional inclusivo em todos os níveis e modalidades. Tal como é enunciado, cabe ao poder público a criação de:

I - (um) sistema educacional inclusivo em todos os níveis e modalidades, bem como o aprendizado ao longo de toda a vida; II - (O) aprimoramento dos sistemas educacionais, visando a garantir condições de acesso, permanência, participação e aprendizagem, por meio da oferta de serviços e de recursos de acessibilidade que eliminem as barreiras e promovam a inclusão plena; III - ( $\bigcirc$ desenvolvimento de um) projeto pedagógico que institucionalize o atendimento educacional especializado, assim como os demais serviços e adaptações razoáveis, para atender 
às características dos estudantes com deficiência e garantir o seu pleno acesso ao currículo em condições de igualdade, promovendo a conquista e o exercício de sua autonomia; IV - (A) oferta de educação bilíngue, em Libras como primeira língua e na modalidade escrita da língua portuguesa como segunda língua, em escolas e classes bilíngues e em escolas inclusivas; (BRASIL, 2015).

O olhar que construímos sobre a legislação direcionada para o atendimento de pessoas com deficiência, na lógica de uma educação inclusiva, permite inferir que do ponto de vista polític tem havido uma atenção crescente sobre a problemática da educação inclusiva. Todavia, se por um lado, a análise permitiu constatar que essa atenção tem sido orientada para o acesso de todos à educação e para concepções curriculares flexíveis e diversificadas, por outro, a legislação analisada denuncia propostas/práticas de concretização da educação inclusiva que a deixam ainda muito prisioneira de uma visão remetida aos alunos com deficiência.

Como argumentamos na primeira parte do artigo, a instituição de uma educação inclusiva pressupõe que os professores se situem como configuradores do currículo, (LEITE; FERNANDES; FIGUEREDO, 2019) predispondo-se para a construção de práticas de contextualização curricular inovadoras e inclusivas (CARVALHO, 2008); (GONZÁLEZ, 2002; FERNANDES et al., 20I3). Não tendo sido possível, no âmbito do objetivo do artigo, ouvir os professores sobre as suas práticas, a opção foi a de, como explicitamos no ponto sobre a metodologia, analisar artigos científicos publicados na plataforma Scielo do Brasil que tivessem como foco práticas curriculares orientadas para a inclusão. É esse olhar analítico que situamos no ponto seguinte do artigo.

\subsection{INCLUSÃO E PRÁTICAS CURRICULARES: UM OLHAR A PARTIR DA PRODUÇÃO ACADÊMICA}

Tendo presente os aspectos mencionados no ponto relativo à metodologia foram, como se referiu, identificados 13 artigos. Uma primeira análise com base nos títulos dos artigos, objetivos, metodologia e resultados/conclusões permitiu organizá-los em quatro grupos que o quadro 2 sistematiza: i) artigos que se reportam à ideia de educação inclusiva e inclusão escolar (artigos I, 2 e 3); ii) artigos que remetem para práticas de inclusão de alunos com deficiência na escola (artigos 4, 5, 6, 7, 8 e 9); iii) artigos que referenciam práticas de inclusão em geral (artigos 10 e II) e iv) artigos que focam a formação de professores na relação com a inclusão (artigos 12 e 13).

Quadro 2 - Artigos selecionados para análise.

\begin{tabular}{llll}
\multicolumn{1}{c}{ Título } & \multicolumn{1}{c}{ Autor(es) } & \multicolumn{1}{c}{ Revista } & Ano \\
\hline I - Caminhos bifurcantes na educação inclusiva: inclusões & Ana Lucia C. HECKERT & Fractal: Revista de & 20 I0 \\
e rebeldias silenciosas na educação pública. & Ricardo Bodart de & Psicologia \\
Descritor: Educação Inclusiva e inclusão escolar & ANDRADE. & &
\end{tabular}


2 - O Profissional da Inclusão Escolar.

Descritor: Educação Inclusiva e inclusão escolar 3 - Inclusão escolar e o planejamento educacional individualizado: estudo comparativo sobre práticas de planejamento em diferentes países.

Descritor: Educação Inclusiva e inclusão escolar 4 - Ver, não ver e aprender: a participação de crianças com baixa visão e cegueira na escola.

Descritor: Práticas de Inclusão na escola

5 - O processo de inclusão de crianças com deficiência auditiva na escola regular: vivências de professores.

Descritor: Práticas de Inclusão na escola

6 - Práticas de Professores Frente ao Aluno com

Deficiência Intelectual em Classe Regular.

Descritor: Práticas de Inclusão na escola

7- Inclusão escolar: um estudo acerca da implantação da proposta em escolas de ensino básico.

Descritor: Práticas de Inclusão na escola

8 - Desafios da educação inclusiva: um estudo sobre práticas de inclusão em escolas da rede regular de ensino na cidade de Santa Rita - PB.

Descritor: Práticas de Inclusão na escola

9 - Professores do Atendimento Educacional

Especializado e a Organização do Ensino para o Aluno com Deficiência Intelectual.

10 - Processos de inclusão e docência compartilhada no III ciclo.

Descritor: Práticas de inclusão na escola

| | - Práticas pedagógicas e inclusão: a sobrevivência da integração nos processos inclusivos.

Descritor: Práticas de inclusão na escola

\section{2 - Formação de professores por meio de pesquisa} colaborativa com vista à inclusão de alunos com deficiência intelectual.

Descritor: Inclusão e formação de Professores

13 - Revisão sistemática acerca das políticas de educação inclusiva para a formação de professores.

Descritor: Inclusão e formação de Professores
Ana DORZIAT

Gabriela TANNÚS-

VALADÃO

Enicéia Gonçalves MENDES

Adriana Lia Friszman de

LAPLANE

Cecília Guarneiri BATISTA

Noemi Vieira de Freitas

RIOS

Beatriz Cavalcanti de A

Caiuby NOVAES

Teresa Cristina Coelho dos

SANTOS

Lúcia de Araújo Ramos

MARTINS

Nilza Sanches Tessaro

LEONARDO

Cristiane Toller BRAY

Solange Pereira Marques

ROSSATO

Ana Maria Meireles

MENDES

Isabel SANCHES

Renata Andrea Fernandes

FANTACINI

Tárcia Regina da Silveira

DIAS

Clarice Salete TRAVERSINI

Maria Luisa Merino de

Freitas XAVIER

Maria Bernadette Castro

RODRIGUES

Maria Isabel Habkcost

DALLA ZEN

Nádia Geisa Silveira de

SOUZA

Hildete Pereira dos ANJOS;

Luciana Barbosa de MELO;

Kátia Regina da SILVA;

Lucélia C. Cavalcante

RABELO.

Elizabete Humai de

TOLEDO

Célia Regina VITALIANO

Maria Amélia INGLES

Samuel

ANTOSZCZYSZEN

Silvia Iris Afonso Lopes

SEMKIV

Jáima Pinheiro de OLIVEIRA

Cadernos de Pesquisa

2013

Revista Brasileira de

Educação

Cadernos CEDES

Revista Brasileira de

Educação Especial

Revista Brasileira de

Educação Especial

Revista Brasileira de

Educação Especial

Educação em Revista

Revista Brasileira de

Educação Especial

Revista Lusófona de

Educação

Educação \& Sociedade

Fonte: elaborado pelas pesquisadoras.

Seguindo a lógica de organização dos artigos, iniciamos com os autores (HECKERT; ANDRADE, 20 l0), através de conversações com professores buscaram cartografar os processos de inclusão gestados nas práticas educacionais. Recorrem aos instrumentos analíticos oferecidos por Michael Hardt e Toni Negri 
(2005), e Michel Foucault (2006) acerca das práticas sociais, dos processos de inclusão e do biopoder. Concluindo que os modos instituídos que tecem a educação produzem o chamado fracasso escolar, eles sugerem que a educação precisa ser desinstitucionalizada no sentido de se compreender que o cotidiano educa mais do que os conteúdos, suplantados inclusive pelo próprio modo de fazer escola, que gera a pertinência de ensinar uns conteúdos e não outros.

No segundo artigo, (DORZIAT, 2013) problematiza condições para uma educação inclusiva, nomeadamente condições profissionais. Recorre à entrevistas a responsáveis de escolas públicas em João Pessoa (Brasil) e em Lisboa (Portugal). Para o objetivo desta pesquisa teve-se em conta apenas os dados relativos ao Brasil. Os resultados indicam que as escolas inclusivas de João Pessoa (Brasil) carecem de professores de educação especial que permitam assegurar condições para a inclusão de todos os alunos.

A autora concluiu com duas grandes ideias: i) não basta inserir fisicamente os alunos historicamente marginalizados na escola. É necessário fazer da educação prioridade, proporcionando-lhe condições adequadas e, sobretudo, desestabilizando as padronizações de desenvolvimento humano, herdadas de visões positivistas; ii) A inclusão não pode ser restrita a alguns (alunos com diferenças marcadas em termos biológicos, étnicos, de gênero, de religião etc.), mas deve envolver todo o sistema educacional. $\bigcirc$ terceiro artigo foca-se na inclusão escolar e no planejamento educacional individualizado (TANNUS-VALADÃO; MENDES, 20 I8). As autoras recorrem à análise da legislação sobre Projeto Educativo Individualizado (PEI) e sobre modelos de execução desse tipo de planejamento em países, a saber: França, Itália, Estados Unidos e Brasil. Para esta pesquisa tem-se em conta apenas os resultados relativos ao Brasil.

Os autores concluem que o Brasil não possui dispositivos legais que garantam que alunos público alvo da educação especial (PAEE) tenham um PEl baseado em suas peculiaridades, constatando que o planejamento é centrado mais nos serviços existentes do que nas necessidades dos alunos. Um olhar síntese sobre estes 3 artigos permite-nos inferir que embora a inclusão e a educação inclusiva esteja proclamada desde a Constituição de 1988, ela parece não ser ainda uma realidade na escola pública brasileira, nomeadamente porque existe falta de professores de educação especial e também por não se verificar alterações nas práticas de planejamento.

Centrando-nos no segundo grupo de artigos, (LAPLANE; BATISTA, 2008) discutem o desenvolvimento e a aprendizagem de crianças com deficiência visual e o modo como apreendem o mundo, bem como o uso de recursos para auxiliar a sua participação na escola. As autoras concluem sobre a importância de se atender a aspectos particulares que a deficiência visual implica, e diligenciar no sentido de se mobilizarem recursos que favoreçam a participação plena dos alunos na vida escolar. Enfatizam também a importância dos alunos serem acompanhados por um professor atento, informado e dinâmico, capaz de identificar antecipadamente as necessidades e interesses dos alunos. Por seu lado, (RIOS; NOVAES, 2009), a partir de relatos de professores, discutem o processo de inclusão de crianças com 
deficiência auditiva em escola regular. Concluem que, pese embora seja reconhecida pelas professoras participantes no estudo que houve evolução das práticas inclusivas, nas escolas continua a prevalecer os pressupostos da integração mais do que os da inclusão. Um dos argumentos justificativos parece ser o da "não preparação dos professores" para intervir com alunos com esta problemática. A tônica na ausência de formação dos professores parece reforçar uma das conclusões do artigo de (LAPLANE; BATISTA, 2008), quando enfatiza a importância de alunos com deficiência serem acompanhados por professores bem (in)formados. A redução do número de alunos, bem como a melhoria dos recursos e equipamentos são também apontados como um aspecto a ter em consideração nas práticas de inclusão de crianças com deficiência.

Com foco nas práticas pedagógicas de professores que intervêm com alunos com deficiência intelectual, (SANTOS; MARTINS, 20 I5), em linha com conclusões do estudo de (RIOS; NOVAES, 2009), constatam que as práticas desenvolvidas pelos professores revelam "um fazer pedagógico" tradicional. De modo a se promoverem práticas de efetiva inclusão, as autoras reconhecem, igualmente, ser necessário maior investimento na formação inicial de professores e de todos os agentes educativos, bem como realizar adequações curriculares, adotando processos de trabalho colaborativo em parceria com outros docentes, e com as famílias.

O estudo de (LEONARDO; BRAY; ROSSATO, 2009) teve por foco processos de implementação dos projetos de Educação Inclusiva no ensino básico, em escolas públicas e privadas, do interior do Paraná. A pesquisa envolveu professores cujas turmas têm incluídos alunos com deficiência, num total de 26 participantes que responderam a um inquérito por questionário. Os resultados evidenciam que quer as escolas públicas, quer as privadas não têm recursos humanos suficientes para desenvolver projetos inclusivos e que os profissionais revelam falta de conhecimentos e de competências para trabalharem com a diversidade dentro da sala de aula, não mobilizando metodologias e recursos didático-pedagógicos adequados às necessidades dos alunos especiais, o que leva as autoras a concluir que as práticas de inclusão escolar são muito restritas.

Na mesma linha de investigação situa-se o artigo de (MENDES; SANCHES, 2009), cuja pesquisa visou compreender práticas de inclusão de alunos com Necessidades Educativas Especiais. Metodologicamente recorreram à entrevista semiestruturada a professores e outros profissionais, gestores e encarregados de educação. Em linha com os resultados de outros estudos, esta pesquisa conclui que a falta de serviços de apoio pedagógico, de condições de trabalho, de relacionamento família/escola, de estrutura física nas escolas, número de alunos em sala, e a falta de preparação do corpo docente constituem fatores que dificultam a implantação de práticas inclusivas.

Numa leitura mais abrangente, (FANTACINI; DIAS, 20I5), propõem-se, a partir da perspectiva de professoras que atuam na equipe de AEE de um município, conhecer e refletir sobre a organização da 
educação inclusiva para o atendimento do aluno com deficiência intelectual nos diferentes espaços educacionais na rede municipal. Concluem que as professoras entrevistadas seguem as orientações da Política Nacional de Educação Especial na Perspectiva da Educação Inclusiva (BRASIL, 2008c) e suas Diretrizes Operacionais (BRASIL, 2008b) quanto à organização e ao funcionamento do AEE. Reconhecem também, na linha de outros estudos analisados, a importância de se melhorar a formação de professores que atuam na educação especial, nomeadamente para aprofundamento de conhecimento sobre adaptações curriculares, área em que revelaram desconhecimento.

Uma análise integrada destes seis artigos permite, para já, inferir que as práticas de inclusão com crianças com deficiência parecem distanciar-se do que é preconizado no discurso legal, designadamente no Art. 59, da LDBEN quanto à adoção de currículos, métodos e recursos educativos que permitam responder eficazmente às necessidades dos alunos, e quanto à capacitação dos professores para o desenvolvimento de práticas de inclusão.

Não referenciando os alunos com deficiência, também os dois últimos artigos do grupo de artigos que remetem para práticas de inclusão na escola trazem leituras pertinentes sobre o processo de inclusão nas escolas. Assim, o artigo de (TRAVERSINI; XAVIER; RODRIGUES; ZEN; SOUZA, 20I2) analisa a implementação do Projeto de Docência Compartilhada em duas escolas municipais, destacando seus limites e possibilidades. Com recurso a registros de reuniões pedagógicas, observações em salas de aula e análise de produção textual de alunos, as autoras concluem que o projeto em questão apresenta potencialidades no que tange: ao exercício compartilhado da docência; à desnaturalização das diferenças entre os alunos; à concretização de aprendizagens cognitivas e sociais. Consideram, todavia, face aos princípios de inclusão que orientam o projeto, que o processo de adequação do currículo tem sido lento.

Também o trabalho de (ANJOS; MELO; SILVA; RABELO, 2013) apresenta uma análise do processo inclusivo, com base em entrevistas a professores de atendimento especializado, professores de sala comum e gestores sobre os conceitos de prática pedagógica e inclusão e sobre práticas inclusivas. Os resultados apontam para um desconhecimento das especificidades de aprendizagem e dos potenciais dos sujeitos e grupos; para a sobrevivência do modelo clínico e para certas iniciativas com caráter mais integrativo do que inclusivo. Os autores concluem sobre a importância de se desenvolverem pesquisas de caráter interventivo participativo, que contribuam para desnaturalizar práticas pedagógicas cristalizadas e promover práticas pedagógicas inclusivas.

Dos artigos que colocam o foco na formação de professores na relação com a inclusão, (TOLEDO; VITALIANO, 2012) investigam sobre a eficácia de um programa de formação de professores numa Escola Estadual de Ensino Fundamental II do Estado do Paraná, com vista a favorecer o processo de inclusão de alunos com deficiência intelectual (DI). Para isso, recorrem, inicialmente, à entrevistas a professoras sobre seus conhecimentos acerca do processo de inclusão de alunos com DI e à observações em sala de aula 
de suas práticas. Em face aos dados obtidos desenvolvem um ciclo de estudos sobre o processo de inclusão educacional, produzindo análises reflexivas sobre as práticas pedagógicas desenvolvidas durante as aulas. No fim da formação entrevistam de novo as professoras com o objetivo de ajuizar sobre os sentidos da formação nas suas práticas. Os resultados mostram que as professoras ampliaram o seu conhecimento sobre educação inclusiva e que houve melhoria na qualidade dos processos de inclusão dos alunos com DI, reconhecendo-se também o trabalho colaborativo entre professores do ensino regular e professor especialista em Educação Especial como essencial para favorecer o processo de inclusão de alunos com DI.

Numa outra perspectiva, o estudo de (INGLES; ANTOSZCZYSZEN; SEMKIV; OLIVEIRA, 20।4) faz uma revisão bibliográfica sobre políticas públicas, com foco para a formação de professores da educação básica que atuam em contextos inclusivos. Dos artigos analisados as autoras concluem que existem muitas reflexões e discussões teóricas sobre as políticas de formação docente e educação inclusiva, mas que poucas dessas produções relatam experiências de práticas pedagógicas que promovam a inclusão. No que se refere, especificadamente, à formação de professores para atender à política de inclusão, a análise permitiu também constatar que o poder político tem vindo a sinalizar a necessidade de se incorporarem conteúdos relacionados com a atenção à diversidade em todos os cursos de graduação.

Um olhar síntese sobre a análise aos 13 artigos permite inferir três principais ideias: a ideia de que as escolas públicas brasileiras não têm ainda asseguradas as condições físicas, de recursos humanos e pedagógicos para garantir a inclusão de todos os alunos; a ideia de que as práticas desenvolvidas pelos professores revelam "um fazer pedagógico" orientado mais por princípios de integração do que de inclusão; e, a ideia de que os professores precisam de se capacitar, através de formação específica, para desenvolver práticas de inclusão mais consistentes.

\section{CONSIDERAÇÕES FINAIS}

Como se explicitou na metodologia, pretendeu-se nesta pesquisa analisar legislação sobre educação inclusiva no Brasil desde a Constituição da República Federativa do Brasil (1988), e artigos com foco em práticas curriculares na escola, publicados na plataforma Scielo do Brasil nos últimos dez anos (2008-20 I 8). Procura-se agora tecer uma leitura articulada desses discursos trazendo ao texto linhas de força que podem configurar algumas pontes entre esses discursos.

No que concerne ao atendimento de alunos com deficiência, os dados parecem permitir inferir que do ponto de vista político tem havido uma atenção crescente sobre a problemática da educação inclusiva. Esta atenção tem sido dirigida não apenas ao acesso de todos à educação, como também à implementação de propostas curriculares promotoras de inclusão. Evoca-se, a título de exemplo, a Lei n. 
10.436/02 (2002b), que reconhece a Língua Brasileira de Sinais - LIBRAS - como meio legal de comunicação e expressão. Todavia, essas proposições politicas orientadas para a inclusão parecem não se terem traduzido ainda de forma evidente nas práticas curriculares dos quotidianos escolares. Como demonstrou a análise dos artigos, as práticas de inclusão estão ainda muito restringidas ao acesso, e muito pouco direcionadas para estratégias de diferenciação pedagógica e de contextualização do currículo, promotoras da inclusão. A este nível pode pois inferir-se haver um certo distanciamento entre discursos legais e discursos teóricos sobre práticas curriculares de inclusão.

Atentando também na LDBEN, no Art. 59, e na evocação que nela é feita sobre a importância de se assegurarem "currículos, métodos, técnicas, recursos educativos e organização específicos para atender às (...) necessidades" de alunos com deficiência, vislumbra-se aqui uma ténue ponte com a tendência expressa em alguns artigos sobre a valorização da formação dos professores para intervirem face à diversidade.

Por outro lado, e como ao longo do artigo fomos sustentando, a instituição de uma educação inclusiva requer, por um lado, a adoção de estratégias de contextualização curricular (CARVALHO, 2008); (GONZÁLEZ, 2002; FERNANDES et al., 2013) e, por outro, que os professores se assumam como configuradores do currículo, (LEITE; FERNANDES; FIGUEREDO, 2019) predispondo-se para a construção de práticas curriculares inovadoras e inclusivas. Neste caso, os resultados tanto dos discursos legais como dos discursos teóricos parecem apontar para uma direção que não é clara. Se alguns estudos permitem concluir que o uso de estratégias e de recursos adequados, associado à remoção das barreiras bem como a atenção à dimensão social da aprendizagem, constituem requisitos para ambientes de aprendizagens favoráveis à aprendizagem autônoma dos alunos, outros revelam que a falta de recursos e de condições físicas e de materiais pedagógicos nas escolas públicas, a dificuldade de os professores se desprenderem de um "fazer pedagógico" tradicional, o número de alunos por turma e a falta de formação especializada dos professores constituem fortes constrangimentos na instituição de uma educação inclusiva. Do ponto de vista da análise legislativa, pese embora se identifique uma tendência discursiva que aponta para uma visão de currículo flexível, e para propostas pedagógico-curriculares assentes na diferenciação, constatou-se também uma coexistência lexical de "professor do ensino regular" e "professor especializado" que remete para propostas/práticas de concretização que parecem ficar prisioneiras de uma visão de educação inclusiva remetida aos alunos com deficiência.

Em face destes elementos parece poder afirmar-se que existe um grande distanciamento entre o que é preconizado nos discursos legais sobre a educação inclusiva ("o expectável") e os discursos sobre as práticas de inclusão ("o fazível"). Dito de outro modo, parece poder concluir-se não existir uma relação consentânea entre enunciados do discurso legal relativos á inclusão e o que os estudos analisados evidenciaram sobre possibilidades de concretização nos quotidianos escolares. 
Num posicionamento de esperança, e de crença na escola pública, queremos salientar os aspetos denunciados pelos estudos analisados sobre a problemática da educação inclusiva de pessoas com deficiência no Brasil, enquanto mote para novas reflexões, quer a nível político, quer pedagógico-curricular. É nesse, e para esse, espaço de debate que este artigo pretende contribuir.

\section{REFERÊNCIAS}

AMADO, J. Manual de investigação qualitativa em educação. Coimbra: Universidade de Coimbra, 20 I 3.

AINSCOW, M. Educação para todos: torná-la realidade. In: AINSCOW, Mel; PORTER, Gordon; WANG, Margaret (Eds.). Caminhos para as escolas inclusivas: desenvolvimento curricular na educação básica. Lisboa: IIE/Ministério da Educação, p. II-3I. B, 1997.

ANJOS, H. P. dos; MELO,L.B.de; SILVA,K.R.da; RABELO,L.C.C.. Práticas pedagógicas e inclusão: a sobrevivência da integração nos processos inclusivos. Educ. Soc., Campinas, v. 34, n. 123, p. 495-507, Jun., 20 I3. Disponível em: http://www.scielo.br/scielo.php?script=sci arttext\&pid=SO I 01 -

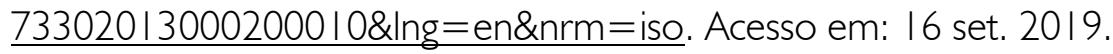

ARMSTRONG, F.; RODRIGUES, D. A Inclusão nas Escolas. Trad. Joana Matias. Fundação Francisco Manuel dos Santos. Lisboa, 2014.

ARMSTRONG, F.; RODRIGUES, D. EDUCAÇÃO INCLUSIVA: culturas escolares, ensino e aprendizagem. Felicity Armstrong. In: A Inclusão nas Escolas. Felicity Armstrong David Rodrigues, p. I3$29,2014$.

BEYER, H. O. Da Integração Escolar à Educação Inclusiva: Implicações Pedagógicas. In: BAPTISTA, Claudio Roberto (org.). Inclusão e Escolarização: Múltiplas Perspectivas. I ${ }^{a}$ reimpressão. Porto Alegre: Editora Mediação, p. 76, 2009.

BOOTH, T. Inclusion and Exclusion in the City: Concepts and Contexts' in Potts, P. (ed) Inclusion in the City, 2002.

BRASIL. Constituição da República Federativa do Brasil. - Brasília: Centro Gráfico do Senado Federal. Constituição da República Federativa do Brasil: Promulgada em 5 de outubro de 1988. Disponível em: http://www.planalto.gov.br/ccivil_03/constituicao/constituicao.htm. Acesso em: 16 de ago. 2019.

BRASIL. Lei de Diretrizes e Bases da Educação Nacional. Ministério da Educação. Lei n. 9.394/96; MEC; Brasilia, 1996.

BRASIL. Ministério da Educação. Resolução CNE/CEB n. 2, de I I de setembro de 200 I. Brasília: MEC/SEESP, 200I.

BRASIL. Diretrizes nacionais para a educação especial na educação básica/ Secretaria de Educação especial. MEC, SEESP. Brasília: 2001.

BRASIL. Ministério da Educação. Secretaria de Educação Especial. Portaria n. 2.678/02. Aprova o projeto da Grafia Braille para a Língua Portuguesa e recomenda o seu uso em todo o território nacional, 2002a. 
BRASIL. Ministério da Educação. Secretaria de Educação Especial. Lei n. 10.436, de 24 de abril de 2002. Dispõe sobre a Língua Brasileira de Sinais - Libras e dá outras providências. Brasília: MEC, 2002b.

BRASIL. Ministério da Educação. Política Nacional de Educação Especial na Perspectiva da Educação Inclusiva. Brasília: MEC, 2008a. Disponível em:

http://portal.mec.gov.br/arquivos/pdf/politicaeducespecial.pdf. Acesso em: 15 ago. 2019.

BRASIL. Decreto n. 6.57I, de 17 de setembro de 2008b. Dispõe sobre o Atendimento Educacional Especializado. Disponível em: camara.leg.br/legin/fed/decret/2008/decreto-

657 |- | 7-setembro-2008-580775-publicacaooriginal- I03645-pe.html. Acesso em: 05 out. 2019.

BRASIL. Decreto n. 6.57I, de 17 de setembro de 2008b. Dispõe sobre o Atendimento Educacional Especializado. Disponível em: camara.leg.br/legin/fed/decret/2008/decreto-

657 I- I 7-setembro-2008-580775-publicacaooriginal- I03645-pe.html. Acesso em: 04 out.2019.

BRASIL. Resolução CNE/CEB 4/2009 - institui as diretrizes para operacionalização do atendimento educacional especializado na Educação Básica na modalidade educação especial, 2009. Disponível em: portal.mec.gov.br/dmdocuments/rceb004_09.pdf. Acesso em: 27 mai. 2019.

BRASIL. Censo Escolar da Educação Básica. Instituto Nacional de Estudos e Pesquisas Educacionais Anísio Teixeira, 2013. Disponível em:

inep.gov.br/educacao basica/censo escolar/resumos tecnicos/resumo tecnico censo educacao basica 2013.pdf. Acesso em: 02 set.2019.

BRASIL. Lei n. 13.I46, de 06 de julho de 2015. Lei Brasileira de Inclusão da Pessoa com Deficiência Estatuto da Pessoa Com Deficiência, 2015. Disponível em:

http://www.planalto.gov.br/ccivil 03/ ato2015-2018/2015/lei/1 3146.htm. Acesso em: 25 jul. 2019.

CARVALHO, R. E. Escola Inclusiva: a reorganização do trabalho pedagógico. Porto Alegre: Mediação, p. I04, 2008.

CORREIA, L. M. Educação Inclusiva ou Educação apropriada? In: Rodrigues, D. (org.). Educação e Diferença. Valores e Práticas para uma Educação Inclusiva. Porto: Porto Editora, p. I23- 142, 200 I.

CORREIA, A. M.; FERNANDES, P. Educação especial: Limites e potencialidades da educação inclusiva. Interritórios: Revista de Educação (BR), 3, 24-48, 2016.

DORZIAT, A. O profissional da inclusão escolar. Cad. Pesqui., São Paulo, v. 43, n. I 50, p. 986- I003, 2013. Disponível em:

http://www.scielo.br/scielo.php?script=sci arttext\&pid =SO I $00157420130003000 \mid$ I $\&$ Ing $=$ en\&nrm $=$ is o. Acesso em: 23 Jan. 2020.

FANTACINI, Renata Andrea Fernandes; DIAS, Tárcia Regina da Silveira. Professores do Atendimento Educacional Especializado e a Organização do Ensino para o Aluno com Deficiência Intelectual. Rev. bras. educ. espec., Marília, v. 21 , n. I, p. 57-74, Mar. 2015. Disponível em:

http://www.scielo.br/scielo.php?script=sci arttext\&pid =S14 1365382015000 I 00057\&lng=en\&nrm=is o. Acesso em: $16 \mathrm{dez} .2019$.

FERNANDES, Preciosa; LEITE, Carlinda; MOURAZ, Ana; FIGUEIREDO, Carla. Curricular contextualization: Tracking the meanings of a concept. The Asia-Pacific Education Researcher, 22(4), 4 I7-425. doi: I 0. 1007/s40299-0 I2-004I- I. JCR; Scopu, 2013. 
FOUCAULT,Michel. Microfísica do Poder. Rio de Janeiro: Graal,2006.

FERNANDES, Preciosa; FIGUEIREDO, Carla. Contextualização curricular: Subsídios para novas significações. Interações, 8(22), I63-177, 2012.

FRASER, N. Reconhecimento sem ética? Lua Nova, São Paulo, 70: I0 I- 138, 2007.

FREIRE, P. Pedagogia do oprimido. Rio de Janeiro: Ed. Paz e Terra, 1987.

GONZÁLEZ, T. J. A. Educação e Diversidade: Bases Didáticas e Organizativas. Porto Alegre: ARTMED Editora, p. 155-159, 2002.

GUIJARRO, M. R. B. Inclusão: um desafio para os sistemas educacionais Ensaios Pedagógicos construindo escolas inclusivas. Brasília: MEC, SEESP, 2005.

HART, Michael; NEGRI,Toni. Império.Rio de Janeiro: Record, 2005.

HECKERT, Ana Lucia C; ANDRADE, Ricardo Bodart de. Caminhos bifurcantes na educação inclusiva: inclusões e rebeldias silenciosas na educação pública. Fractal, Rev. Psicol., Rio de Janeiro, v. 22, n. 3, p. 497-5 I 2, Dec. 20 I0. Disponível em:

http://www.scielo.br/scielo.php?script=sci arttext\&pid $=S 198402922010000900004 \& \mid n g=e n \& n r m=$ is o. Acesso em: 16 dez. 2019.

INGLES, Maria Amélia; ANTOSZCZYSZEN,Samuel; SEMKIV, Silvia Iris Afonso Lopes; OLIVEIRA, Jáima Pinheiro. Revisão sistemática acerca das políticas de educação inclusiva para a formação de professores.

Rev. bras. educ. espec., Marília, v. 20, n. 3, p. 46I-478, Sept. 20I4. Disponível em: http://www.scielo.br/scielo.php?script=sci_arttext\&pid=SI $4|3653820| 40003000 \mid$ I \& Ing=en\&nrm=is o. Acesso em: 16 dez. 2019.

KRIPPENDORF, Klaus. Content analysis: an introduction to its methodology. Beverly Hills: Sage, 2003.

LAPLANE, A. L. F. de. O que os dados do Censo Escolar revelam sobre as Barreiras à Inclusão? Dourado/MS: Educação e Fronteiras On-Line, v. 5, n. 13 p. 7-20, maio/ag., 2015.

LAPLANE, Adriana Lia Friszman de; BATISTA, Cecília Guarneiri. Ver, não ver e aprender: a participação de crianças com baixa visão e cegueira na escola. Cad. CEDES, Campinas, v. 28, n. 75, p. 209-227, Aug. 2008. Disponível em:

http://www.scielo.br/scielo.php?script=sci_arttext\&pid=SOI $0132622008000200005 \& \mid n g=e n \& n r m=$ is o. Acesso em: $16 \mathrm{dez} .2019$.

LEONARDO, Nilza Sanches Tessaro; BRAY, Cristiane Toller; ROSSATO, Solange Pereira Marques. Inclusão escolar: um estudo acerca da implantação da proposta em escolas de ensino básico. Rev. Bras. Educ. espec., Marilia, v. I5, n. 2, p. 289-306, Aug. 2009. Disponível em: http://www.scielo.br/scielo.php?script=sci_arttext\&pid=S141365382009000200008\&lng=en\&nrm=is o. Acesso em: 16 dez. 2019.

LEITE, Carlinda; FERNANDES, Preciosa. Desafios para um currículo escolar comprometido com a inclusão. Educação: Temas e Problemas, 3, 203-215, 2007. 
LEITE, Carlinda; FERNANDES, Preciosa; FIGUEIREDO, Carla. National curriculum vs curricular contextualisation: Teachers perspectives. Educational Studies. Advance online publication. doi: I 0. I080/03055698.2019. I570083 JCR; Scopus, 2019.

MENDES, Ana Maria Meireles; SANCHES, Isabel. Desafios da Educação Inclusiva: um estudo sobre práticas de inclusão em escolas da rede regular de ensino na cidade de Santa Rita - PB. Rev. Lusófona de Educação, Lisboa, n. I4, p. 204-205, 2009. Disponível em:

http://www.scielo.mec.pt/scielo.php?script=sci arttext\&pid =SI 64572502009000200025\&lng=pt\&nrm =iso. Acesso em: 21 jan. 2020.

ONU. Declaração Universal dos Direitos Humanos. Assembleia Geral das Nações Unidas em Paris. 10 dez. 1948.

ONU. Transforming our world: the 2030. Agenda for Sustainable Development, 2016.

RAZABONI JUNIOR, R.B.; LEÃO JUNIOR, T. M. de A.; SANCHES, R. C. F. A educação inclusiva para pessoas com deficiência e o papel da UNESCO. Revista da Faculdade de Direito da UFRGS, Porto Alegre, n. 38, p. 140-153, ago. 2018.

RIOS, Noemi Vieira de Freitas; NOVAES, Beatriz Cavalcanti de A. Caiuby. O processo de inclusão de crianças com deficiência auditiva na escola regular: vivências de professores. Rev. bras. educ. espec., Marília, v. 15, n. I, p. 8I-98, Apr. 2009. Disponível em:

http://www.scielo.br/scielo.php?script $=$ sci arttext\&pid $=S \mid 413-$

65382009000 100007\&lng=en\&nrm=iso. Acesso em: 16 dez. 2019.

RODRIGUES, D. (2017) IN SOFIATO, Cássia Geciauskas; ANGELUCCI, Carla Biancha. Educação inclusiva e seus desafios: uma conversa com David Rodrigues. Educ. Pesqui., São Paulo, v. 43, n. I, p. 283-295, Mar 2017. Disponível em:

http://www.scielo.br/scielo.php?script=sci arttext\&pid=SI $51797022017000100283 \&$ lng $=$ en\& $\mathrm{nrm}=$ is o. Acesso em 06 Mar. 2020.

ROLDÃO, M. Diferenciação Curricular Revisitada. PORTO: PORTO EDITORA, 2003.

SANTOS, Teresa Cristina Coelho dos; MARTINS, Lúcia de Araújo Ramos. Práticas de Professores Frente ao Aluno com Deficiência Intelectual em Classe Regular. Rev. bras. educ. espec., Marília, v. 2 I, n. 3, p. 395-408, Sept. 2015. Available from

http://www.scielo.br/scielo.php?script=sci_arttext\&pid=SI4 I3653820 I 5000300395\&lng=en\&nrm=is o. Acesso em: 16 dez. 2019.

STOER, S. Construindo a escola democrática através do campo da 'recontextualização pedagógica'.

Educação Sociedade \& Culturas, n. I, p. 7-27, 1994.

TANNUS-VALADÃO, Gabriela; MENDES, Enicéia Gonçalves. Inclusão escolar e o planejamento educacional individualizado: estudo comparativo sobre práticas de planejamento em diferentes países.

Rev. Bras. Educ., Rio de Janeiro, v. 23, e230076, 2018. Disponível em:

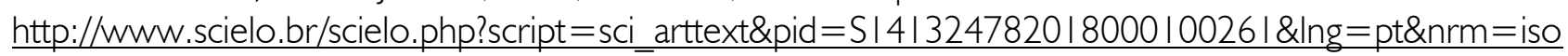
. Acesso em: 16 dez. 2019.

THARENOU, P.; DONOHUE, R.; COOPER, B. Management research methods. Port Melbourne: Cambridge University Press, 2007. 
TOLEDO, Elizabete Humai de; VITALIANO, Célia Regina. Formação de professores por meio de pesquisa colaborativa com vistas à inclusão de alunos com deficiência intelectual. Rev. Bras. Educ. espec., Marília, v. I8, n. 2, p. 319-336, June 2012. Disponível em:

http://www.scielo.br/scielo.php?script =sci arttext\&pid=S1413-

653820120002000 I0\&lng=en\&nrm=iso. Acesso em: 16 dez. 2019.

TRAVERSINI, Clarice Salete et al. Processos de inclusão e docência compartilhada no III ciclo. Educ. rev., Belo Horizonte, v. 28, n. 2, p. 285-308, June 2012. Disponível em:

http://www.scielo.br/scielo.php?script=sci arttext\&pid=SOI02-

469820120002000 I 3\&lng=en\&nrm=iso. Acesso em: 16 dez. 2019.

UNESCO. Declaração mundial sobre educação para todos. Plano de ação para satisfazer as necessidades básicas de aprendizagem. Jomtiem - Tailândia, 1990.

UNESCO. Coordenadoria Nacional para a Integração da Pessoa Portadora de Deficiência (CORDE). Declaração de Salamanca de princípios, política e prática para as necessidades educativas especiais. Brasília: CORDE, 1994.

UNESCO. Manual para garantir inclusão e equidade na educação. Brasília: p. 47, 2019.

\section{COMO CITAR ESSE ARTIGO}

\section{Associação Brasileira de Normas Técnicas (ABNT)}

FERNANDES, Preciosa; DUARTE, Ana Maria Tavares. Educação Inclusiva de Pessoas com Deficiência no Brasil: construindo pontes entre discursos políticos e discursos teórico-curriculares. Debates em Educação, Maceió, v. I2, p. 5I4-535, set. 2020. ISSN 2175-6600. Disponível em:

https://www.seer.ufal.br/index.php/debateseducacao/article/view/9766. Acesso em: dd mmm. aaaa.

\section{American Psychological Association (APA)}

Fernandes, P., \& Duarte, A. (2020). Educação Inclusiva de Pessoas com Deficiência no Brasil: construindo pontes entre discursos políticos e discursos teórico-curriculares. Debates em Educação, I 2(Esp), 5। 4535. doi: https://doi.org//0.28998/2 175-6600.2020v12nEspp5|4-535 